\title{
An Invertebrate Coagulation System Activated by Endotoxin: Evidence for Enzymatic Mediation
}

\author{
Neal S. Young, Jack Levin, and Robert A. Prendergast \\ From the Department of Medicine and The Wilmer Institute, The Johns \\ Hopkins University School of Medicine and Hospital, Baltimore, \\ Maryland 21205, and the Marine Biological Laboratory, \\ Woods Hole, Massachusetts 02543
}

A в S T RACT Lysates prepared from the amebocytes of Limulus polyphemus, the horseshoe crab, are gelled by endotoxin. Studies were carried out to characterize the components of amebocyte lysate and to examine the kinetics of their reaction with endotoxin. Analysis of amebocyte lysate using sucrose density gradients showed two peaks at $46 \%$ and $86 \%$ gradient volumes. G50 and G75 Sephadex column chromatography resulted in three protein peaks. One fraction contained a clottable protein, which had a molecular weight of approximately 27,000 , and was heat stable. Another fraction contained a high molecular weight, heat labile material, which was activated by endotoxin and reacted with the clottable protein to form a gel. The rate of the reaction between endotoxin and amebocyte lysate was dependent upon the concentration of endotoxin and the concentration of the fraction containing the high molecular weight material. The activity of this fraction was inhibited by diisopropyl fluorophosphate, parachloromercuribenzoate, and para-chloromercuriphenyl sulfonate, suggesting that enzymatic activity depended upon serine hydroxyl and sulfhydryl groups. The reaction between endotoxin and the fractions of lysate was temperature and $\mathrm{pH}$ dependent. The data suggest that endotoxin activates an enzyme which then gels the clottable protein contained in amebocyte lysate.

\section{INTRODUCTION}

The blood coagulation system of Limulus polyphemus, the horseshoe crab, is contained in amebocytes, the circu-

This work was presented in part at the Annual Meeting of the Federation of American Societies for Experimental Biology, 14 April 1971 (1).

Dr. Levin is a John and Mary R. Markle Scholar in Academic Medicine, and recipient of a Research Career Development Award (5 KO4 HE 29906).

Dr. Prendergast is a Research to Prevent Blindness, Inc. Professor. lating blood cells (2). Lysates prepared from washed amebocytes are gelled by endotoxin, and the rate of reaction is dependent upon the concentration of endotoxin $(2,3)$. An assay based on the reaction of the lysate with endotoxin is the most sensitive method now available for the detection of endotoxin, in vitro (2-4). Amebocyte lysate has been used clinically to detect endotoxin in the biological fluids of patients suspected of having gram-negative sepsis (5). The current studies were carried out to characterize the components of this coagulation system.

Amebocyte lysate was fractionated using Sephadex column chromatography and sucrose density gradient analysis. One fraction contained a low molecular weight, heat stable, clottable protein that constituted $50 \%$ of the total protein in amebocyte lysate. Another fracion contained a high molecular weight, heat labile, accelerator of coagulation, which was activated by endotoxin, and had properties consistent with a proteolytic enzyme(s) that catalyzed gelation of the clottable protein. The effect of endotoxin upon this primitive coagulation mechanism is perhaps analogous to its effect on mammalian coagulation mechanisms.

\section{METHODS}

Amebocyte lysate. Lysates of amebocytes, the circulating blood cells of the horseshoe crab (Limulus), were prepared at the Marine Biological Laboratory, Woods Hole, Mass., as described previously (2). Amebocytes were collected in $\mathrm{N}$-ethyl maleimide (final concentration was $5 \times 10^{-3} \mathrm{M}$ ), washed, and lysed by the addition of sterile, pyrogen-free distilled water (The Cutter Laboratories, Berkeley, Calif.). Cellular debris was removed by centrifugation at $1,000 \mathrm{~g}$, and the supernatant amebocyte lysate stored at $4^{\circ} \mathrm{C}$ for up to 18 months. Each batch of lysate was tested for reactivity with endotoxin and detected as little as $0.001-0.005 \mu \mathrm{g} / \mathrm{ml}$ of Escherichia coli endotoxin. Lysate was lyophilized and reconstituted to twice its original concentration in sterile, pyrogen-free water before fractionation.

Endotoxin. E. coli lipopolysaccharide B, 026: B6, Boivin method, Lot No. 3920-25 (Difco Laboratories, Detroit, 
Mich.) was diluted in sterile, pyrogen-free $0.9 \%$ sodium chloride (Cutter Laboratories) before each group of experiments. Endotoxins prepared from E. coli, strains UK-111 and $0-111$, Proteus vulgaris ("E" Pyrogen, Organon Laboratories, Surrey, England), and Serratia marcescens (prepared by Dr. A. Nowotny, Temple University) produced similar results in representative experiments.

Preparation of glassware and reagents. All glassware and solutions were sterilized by autoclaving, and glassware was made pyrogen-free with dry heat $\left(180^{\circ} \mathrm{C}\right.$ for $\left.3-4 \mathrm{hr}\right)$. Plastic components were gas sterilized.

Measurement of the reaction between endotoxin and amebocyte lysate. Endotoxin and lysate or its fractionated components were incubated at $37^{\circ} \mathrm{C}$ in a waterbath for $4 \mathrm{hr}$, using stoppered $10 \times 75 \mathrm{~mm}$ glass test tubes. Each reaction mixture consisted of equal volumes (usually $0.075-0.1 \mathrm{ml}$ ) of lysate (or its fractions) and endotoxin. The incubation mixtures usually were observed at $15 \mathrm{~min}$ intervals during the $1 \mathrm{st} \mathrm{hr}$, at hourly intervals during the next $3 \mathrm{hr}$, and then less frequently until $24 \mathrm{hr}$ had elapsed. The reaction was graded using a previously described system which has been shown to correlate with quantitative measurements of light scattering or optical density $(2,3,6)$. Flocculation $(F)$ was the first detectable change noted after the addition of endotoxin. A definite increase in viscosity (V), associated with a further increase in opacity, followed flocculation. A solid gel $(\mathrm{G})$ represented the maximum end point achieved. Two independent observers graded all experimental reactions.

In some experiments, continuous measurements of optical density were carried out at room temperature using a Beckman DU spectrophotometer (Beckman Instruments, Fullerton, Calif.) and Gilford recording apparatus (Gilford Instrument Labs, Inc., Oberlin, Ohio).

Fractionation of lysate by column chromatography and sucrose density gradient analysis. G50 and G75 Sephadex column chromatography was carried out in $45 \times 2.5 \mathrm{~cm}$ columns at $4^{\circ} \mathrm{C}$ using sterile, pyrogen-free, unbuffered mammalian Ringer's solution (Cutter Laboratories), and plastic, pyrogen-free tubing. The columns were washed initially with 1-2 liters of Ringer's solution to remove endotoxin, and the effluent tested for the presence of endotoxin by the reaction with amebocyte lysate. The $\mathrm{pH}$ of the effluent was 6.5 . The flow rate of the columns was $15 \mathrm{ml} / \mathrm{hr}$. Approximately $2 \mathrm{ml}$ of concentrated whole lysate (protein concentration 10-25 $\mathrm{mg} / \mathrm{ml}$ ) was weighted with sterile, pyrogen-free dextrose (Cutter Laboratories) to produce a final concentration of $10 \%$ dextrose. After determination of the concentration and distribution of protein, fractions from each of the peaks were pooled, lyophilized, and reconstituted to concentrations approximately equivalent to their concentrations in whole lysate.

$10-40 \%$ linear sucrose density gradient analysis in $0.01 \mathrm{M}$ acetate buffer, $\mathrm{pH}$ 5.2, was performed with concentrated whole lysate (protein concentration $40 \mathrm{mg} / \mathrm{ml}$ ). The gradient was centrifuged at $35,000 \mathrm{rpm}(100,000 \mathrm{~g})$ for $18 \mathrm{hr}$ in a model $\mathrm{L}$ ultracentrifuge using an SW 50L rotor (Spinco Division, Beckman Instruments, Palo Alto, Calif.).

Preparation of rabbit antilysate antibody. New Zealand white rabbits were injected with whole amebocyte lysate or fractions prepared from Sephadex column chromatography. The antigen ( $2 \mathrm{mg}$ ) was emulsified with complete Freund's adjuvant (Difco Laboratories) and injected i.m. in equally divided portions into four sites, and subcutaneously into the nape of the neck. Subsequently, each animal received booster injections at 2 -wk intervals. The animals were bled from

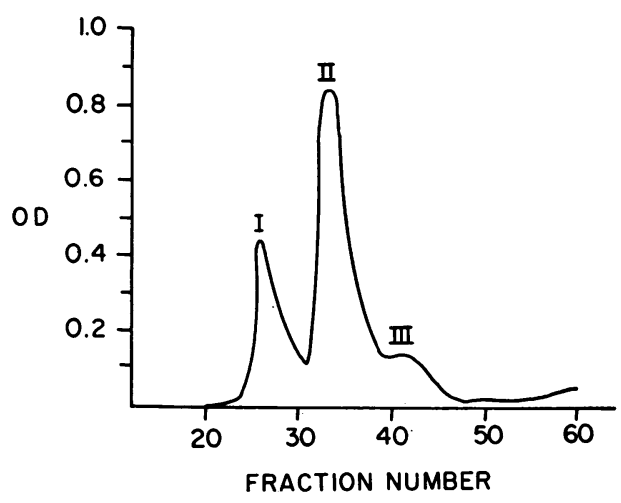

Figure 1 Chromatographic fractionation of amebocyte lysate by G50 Sephadex. Three major fractions were observed and designated I, II, and III. Fraction I was in the void volume.

the marginal ear vein at 4 and $6 \mathrm{wk}$, and serum was prepared and stored at $4^{\circ} \mathrm{C}$.

Immunologic analysis. Ouchterlony agar diffusion in $1.1 \%$ agarose and microimmunoelectrophoresis were performed as described previously $(7,8)$.

Protein determinations. Protein concentrations were determined by a modification of the Folin method (9).

Reagents. Sodium phosphate and veronal buffers were prepared according to standard laboratory procedures (10). Alpha, alpha'-dipyridyl (Fisher Scientific Company, Pittsburgh, Pa.), diisopropyl fluorophosphate (DIFP; ${ }^{1}$ Mann Research Labs, New York), disodium ethylenediaminetetraacetate (EDTA; Fisher), iodacetic acid (Eastman Organic Chemicals, Kingsport, Tenn.), N-ethyl maleimide (NEM; Mann), para-chloromercuribenzoic acid, sodium salt (pCMB; Mann), para-chloromercuriphenyl sulfonic acid, monosodium salt (pCMS ; Sigma Chemical Co., St. Louis, Mo.), and polyvinylsulfuric acid, potassium salt (Eastman Organic Chemicals) were used to evaluate some properties of amebocyte lysate. Stock solutions $\left(10^{-2} \mathrm{M}\right)$ were prepared with sterile, pyrogen-free distilled water and stored at $4^{\circ} \mathrm{C}$, except for DIFP and NEM, which were prepared freshly each day, and $\mathrm{pCMB}$, of which a saturated solution was prepared.

\section{RESULTS}

Column chromatography and sucrose density gradient analysis of amebocyte lysate. Fractionation of amebocyte lysate by Sephadex G50 and G75 column chromatography resulted in three peaks of protein concentration which were designated I, II, and III (Fig. 1). Fraction I was in the void volume of both columns. Preparations of whole lysate had a mean protein concentration of $10 \mathrm{mg} / \mathrm{ml}$; fraction I constituted approximately $30 \%$ of whole lysate by weight, fraction II was $50 \%$, and fraction III was $15 \%$. Materials from the peak of fraction II had a molecular weight of approxi-

${ }^{1}$ Abbreviations used in this paper: DIFP, diisopropyl fluorophosphate; NEM, N-ethyl maleimide; pCMB, parachloromercuribenzoic acid, sodium salt; pCMS, para-chloromercuriphenyl sulfonic acid, monosodium salt. 


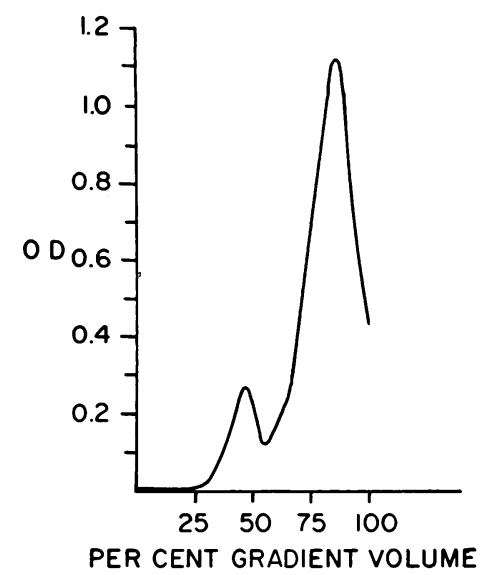

FIGURE 2 Sucrose density gradient analysis of amebocyte lysate. $10-40 \%$ sucrose density gradient analysis of acidified lysate demonstrated two peaks at $46 \%$ and $86 \%$ gradient volumes.

mately 27,000 , as determined by comparison with markers of known molecular weight using G75 Sephadex column chromatography. Fraction I could not be separated into its component parts by column chromatography with Sephadex G200. Sucrose density gradient analysis of acidified lysate revealed two peaks at $46 \%$ and $86 \%$ gradient volumes (Fig. 2).

Immunoelectrophoretic analysis of amebocyte lysate. Immunoelectrophoresis of whole lysate using rabbit antilysate serum demonstrated at least six components (Fig. 3). Immunoelectrophoresis of the fractions pro-

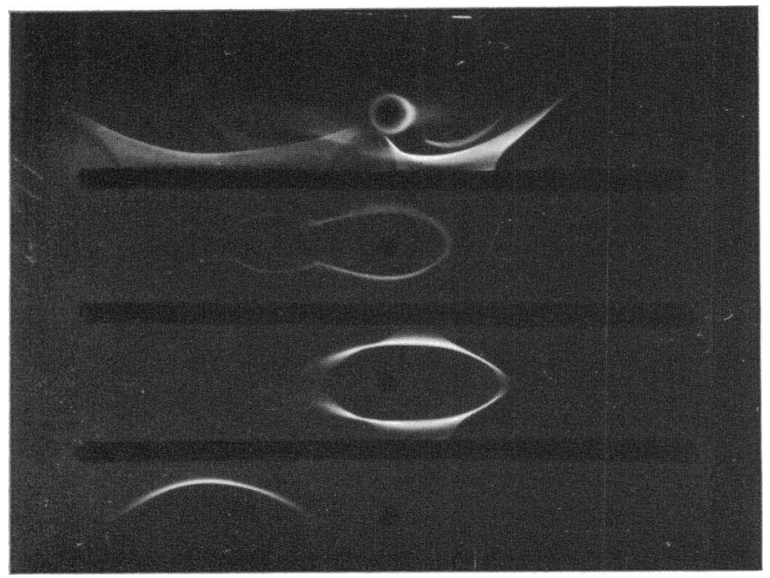

FigURE 3 Immunoelectrophoretic analysis of amebocyte lysate and Sephadex fractions. The wells were filled (from top to bottom) with whole lysate, fraction I, fraction II, and fraction III, and electrophoresis was performed. The troughs then were filled with antiserum to whole lysate. Fraction I contained two major precipitin lines; fraction II and fraction III each demonstrated a single precipitin line. The anode is on the left.

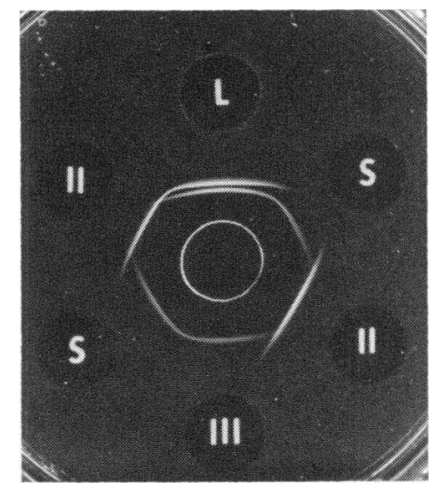

FIGLRE 4 Ouchterlony analysis of supernatant obtained after gelation of amebocyte lysate by endotoxin. Sephadex fraction II (II) and the supernatant (S) were placed in two lateral wells, each. The upper well contained whole lysate (L) and the lower well contained fraction III (III). The precipitin line of fraction II formed an arc of identity with one precipitin line of the whole lysate. Fraction II was absent from the supernatant, but fraction III remained present.

duced by column chromatography showed two major precipitin lines for fraction I at the $\alpha_{2}$ and $\gamma_{1}$ positions, and single lines for fraction II ( $\gamma_{1}$ position) and fraction III ( $\alpha_{1}$ position) (Fig. 3). Immunoelectrophoresis of the two peaks obtained from sucrose density gradient analysis showed that the $\alpha_{2}$ component of fraction I was contained in the peak at $46 \%$ gradient volume; and the $\gamma_{1}$ component of fraction I and fractions II and III were contained in the peak that was present at $86 \%$ of the gradient volume.

To determine which fractions were utilized during the reaction with endotoxin, whole lysate was gelled by endotoxin $(10 \mu \mathrm{g} / \mathrm{ml})$ and the gel was removed by centrifugation at $30,000 \mathrm{rpm}$ for $20 \mathrm{~min}$ at $4^{\circ} \mathrm{C}$. The supernatant obtained was not gelled by the subsequent addition of endotoxin. The supernatant contained fraction III but did not contain fraction II on Ouchterlony analysis (Fig. 4), indicating that fraction II was utilized during the reaction with endotoxin. Immunoelectrophoretic analysis indicated that the fast $\left(\alpha_{2}\right)$ component of fraction I remained present in the supernatant. The slow $\left(\gamma_{1}\right)$ component of fraction I either was diminished or absent, and its detection in the supernatant depended upon the initial concentration.

Reaction of fractions of amebocyte lysate with endotoxin. Sephadex fractions I, II, and III were lyophilized and reconstituted to protein concentrations of 10 $\mathrm{mg} / \mathrm{ml}$. Addition of endotoxin (final concentration 1 $\mu \mathrm{g} / \mathrm{ml}$ ) did not produce gelation of fractions I or III, alone or in combination. This concentration $(1 \mu \mathrm{g} / \mathrm{ml})$ of endotoxin gelled fraction II, although less rapidly than it gelled whole lysate (Fig. 5). The gel formed after the addition of endotoxin to fraction II was more friable than that formed from whole lysate. Gels 


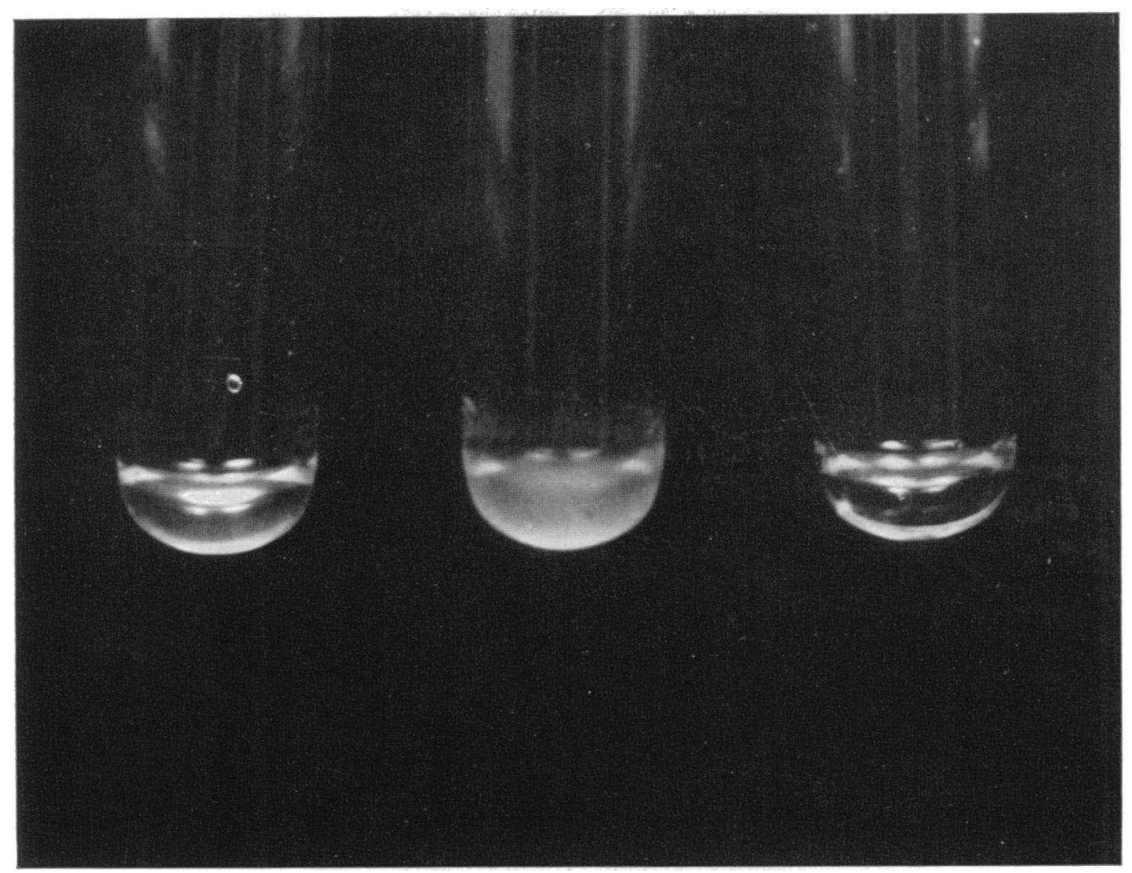

FIGURE 5 Reaction of Sephadex fractions of amebocyte lysate with endotoxin. From left to right, tubes contained fractions I, II, or III $(10 \mathrm{mg} / \mathrm{ml})$ obtained from Sephadex column chromatography. Only fraction II gelled following the addition of endotoxin.

formed from whole lysate or fraction II were insoluble in $8 \mathrm{~m}$ urea or $2 \mathrm{~m} 2$-mercaptoethanol.

Addition of fraction I to fraction II accelerated the rate of the reaction between fraction II and endotoxin
(Fig. 6), and the accelerative effect was proportional to the concentration of fraction I. In other experiments carried out at $37^{\circ} \mathrm{C}$, fraction $\mathrm{I}$, at a concentration $(0.06$ $\mathrm{mg} / \mathrm{ml}$ ) equivalent to $1 / 50$ its concentration in whole

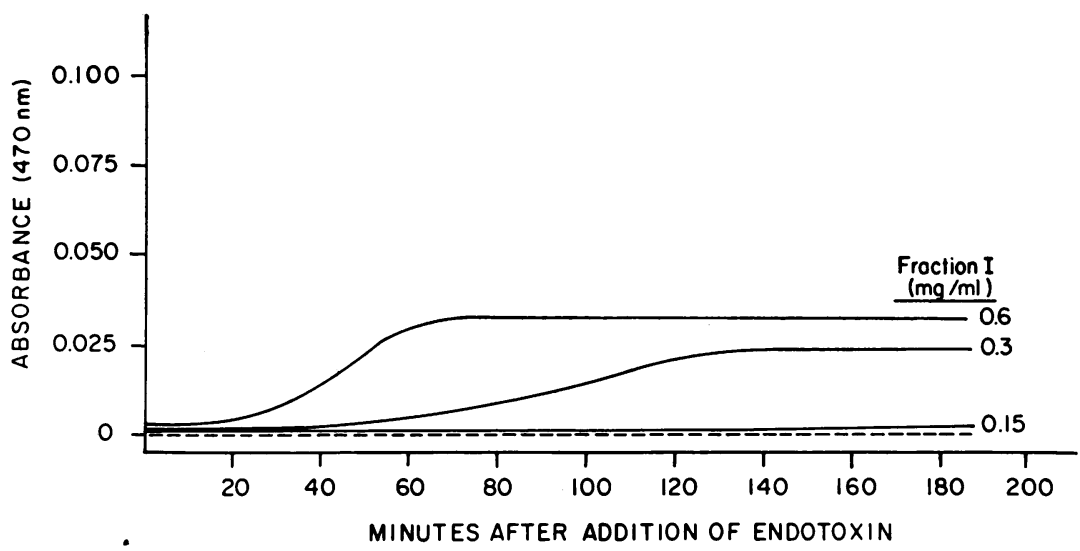

FIGURE 6 The effect of various concentrations of fraction I on the reaction of fractions I and II with endotoxin. The reaction mixtures consisted of $0.01 \mathrm{ml}$ of fraction $I$, in the concentrations indicated, plus $0.1 \mathrm{ml}$ of fraction II $(5 \mathrm{mg} / \mathrm{ml})$ and $0.1 \mathrm{ml}$ of endotoxin $(2.5 \mu \mathrm{g} / \mathrm{ml})$. The control, indicated by the dotted line, was obtained by the addition of sodium chloride $(0.9 \%)$ instead of endotoxin to a reaction mixture which contained $5 \mathrm{mg} / \mathrm{ml}$ of fraction II and $0.6 \mathrm{mg} / \mathrm{ml}$ of fraction I. The records are direct tracings of continuous recordings of increase in optical density. The rate of increase in optical density was proportional to the concentration of fraction I. Results of a representative experiment are shown. 
lysate, accelerated the reaction. The concentration of endotoxin that was required to produce gelation of fraction II was lower if the reaction mixture contained fraction I. The effects of fraction I were diminished by heating at $56^{\circ} \mathrm{C}$ for $30 \mathrm{~min}$, and destroyed by heating at $64^{\circ} \mathrm{C}$ for $20 \mathrm{~min}$.

The rate of the reaction was not altered when the concentration of fraction II was varied (Fig. 7). However, the degree of gelation and the optical density were proportionate to the concentration of fraction II. The activity of fraction II was not destroyed by heating at $64^{\circ} \mathrm{C}$ for $20 \mathrm{~min}$. Protein from fraction III had no effect on gelation.

Effect of preincubation of fraction I with endotoxin. Preincubation of fraction I with endotoxin accelerated the rate of gelation of fraction II (Fig. 8). In other experiments, the degree of acceleration was proportional to preincubation times from 15-120 min, but longer periods of preincubation (to $4 \mathrm{hr}$ ) did not produce additional acceleration. The product that resulted from the preincubation of fraction $I$ and endotoxin (activated $\mathrm{I}$ and designated $\mathrm{I}_{\mathrm{a}}$ ) was heat labile. No accelerative effect was observed when either fraction II and endotoxin or fractions I and II were preincubated before addition of the third component.

Effects of temperature and $p H$. The rate of reaction between endotoxin and fractions I and II was

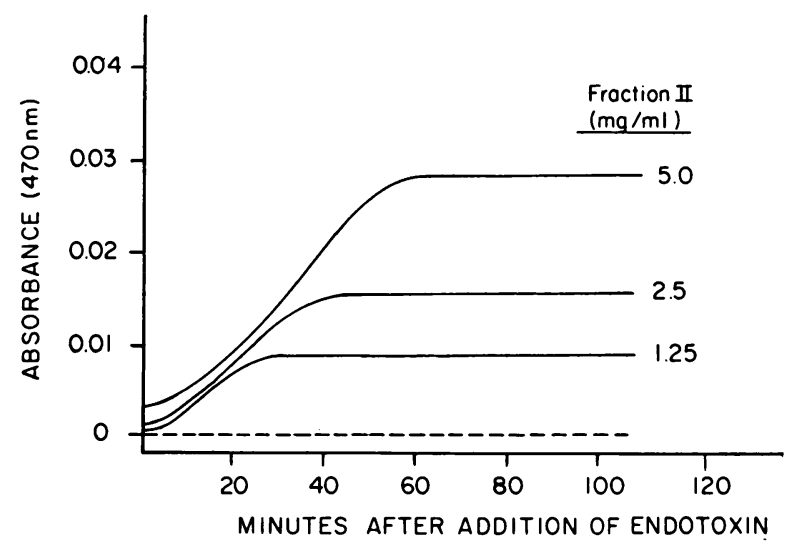

FIgURE 7 The effect of various concentrations of fraction II on the reaction of fractions I and II with endotoxin. The reaction mixtures consisted of $0.1 \mathrm{ml}$ of fraction II, in the concentrations indicated, plus $0.01 \mathrm{ml}$ of fraction I $(6 \mathrm{mg}$ / $\mathrm{ml})$ and $0.1 \mathrm{ml}$ of endotoxin $(2.5 \mu \mathrm{g} / \mathrm{ml})$. The control, indicated by the dotted line, was obtained by the addition of sodium chloride $(0.9 \%)$ instead of endotoxin to a reaction mixture which contained $0.6 \mathrm{mg} / \mathrm{ml}$ of fraction $\mathrm{I}$ and $5 \mathrm{mg} / \mathrm{ml}$ of fraction II. The records are direct tracings of continuous recordings of increase in optical density. The rate of increase in optical density was independent of the concentration of fraction II, but the maximum optical density was proportional to the concentration of fraction II. Results of a representative experiment are shown.

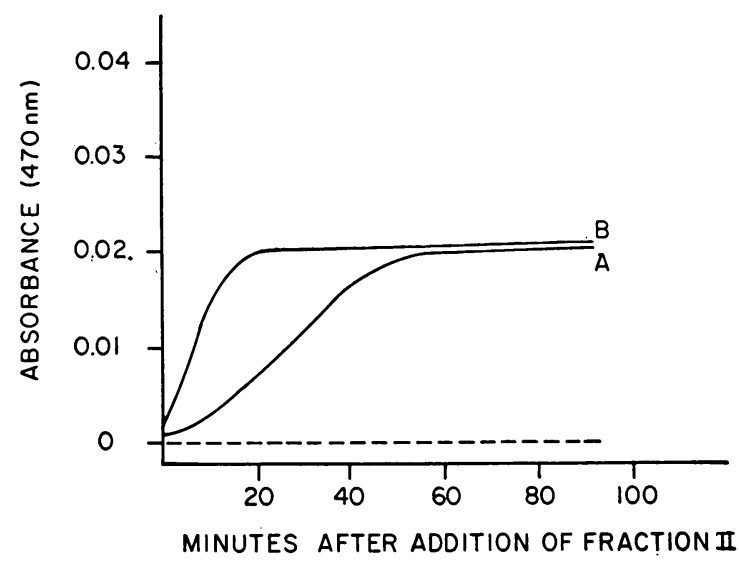

FIGURE 8 The effect of preincubation of fraction $\mathrm{I}$ and endotoxin on the reaction of fractions I and II with endotoxin. Endotoxin $(0.1 \mathrm{ml}, 5 \mu \mathrm{g} / \mathrm{ml})$ was incubated with fraction I $(0.01 \mathrm{ml}, 6 \mathrm{mg} / \mathrm{ml})$ at $37^{\circ} \mathrm{C}$. Fraction II $(0.1 \mathrm{ml}$, $5 \mathrm{mg} / \mathrm{ml}$ ) was added either immediately (A) or $60 \mathrm{~min}$ later (B). The control, indicated by the dotted line, was obtained by the addition of sodium chloride $(0.1 \mathrm{ml}, 0.9 \%)$ to fractions I and II. The records are direct tracings of continuous recordings of increase in optical density. Preincubation of fraction I with endotoxin increased the subsequent rate of increase in optical density when fraction II was added. Results of a representative experiment are shown.

dependent upon the temperature and increased with temperature in the range studied (Fig. 9). Preincubation of fraction $\mathrm{I}$ and endotoxin at $4^{\circ} \mathrm{C}$ did not accelerate the subsequent reaction with fraction II at $37^{\circ} \mathrm{C}$. A latent interval remained before the onset of reaction with fraction II. In other experiments, fraction I and endotoxin were preincubated for $1 \mathrm{hr}$ at $37^{\circ} \mathrm{C}$, fraction II was added, and the reaction tube incubated at $4^{\circ} \mathrm{C}$. The reaction with fraction II initially was accelerated, but the resultant gel was abnormally friable. This indicated that fraction I had been activated, but gel formation was inhibited by the low temperature.

The reaction between endotoxin and fractions $I$ and II was $\mathrm{pH}$ dependent with a maximum of approxi-

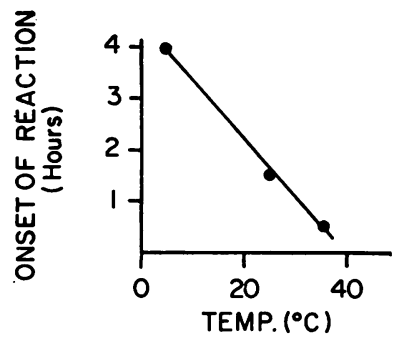

Figure 9 The effect of temperature upon the onset of the reaction between fractions I and II with endotoxin. Each reaction mixture consisted of $0.005 \mathrm{ml}$ of fraction $\mathrm{I}(6 \mathrm{mg} /$ $\mathrm{ml}), 0.05 \mathrm{ml}$ of fraction II $(5 \mathrm{mg} / \mathrm{ml})$, and $0.05 \mathrm{ml}$ of endotoxin $(1 \mu \mathrm{g} / \mathrm{ml})$. The time of onset of reaction decreased as the temperature of incubation increased. 
mately $\mathrm{pH} 7.5$ (Fig. 10). At $\mathrm{pH} 5.7$ and 8.6 only a minimal reaction occurred.

Effects of inhibitors of enzymatic reactions. The individual components of the reaction were preincubated in phosphate buffer, $\mathrm{pH} 7.5$, with various inhibitors for $10 \mathrm{~min}$ at $37^{\circ} \mathrm{C}$. The reaction then was initiated by addition of the remaining components.

Gelation of whole lysate by endotoxin (0.001-0.01 $\mu \mathrm{g} / \mathrm{ml}$ ) was inhibited by preincubation of the lysate with low concentrations $\left(10^{-5}-10^{-6} \mathrm{M}\right)$ of DIFP, $\mathrm{pCMB}$, or pCMS, and polyvinylsulfate $\left(10^{-8} \mathrm{M}\right)$. However, demonstration of inhibition was dependent upon the relative concentrations of inhibitor and endotoxin. Other inhibitors, including metal binders, had no effect on the reaction (Table I).

Incubation of fraction I $(0.6 \mathrm{mg} / \mathrm{ml})$ with DIFP $\left(10^{-4} \mathrm{M}\right), \mathrm{pCMB}\left(10^{-4} \mathrm{M}\right)$, or $\mathrm{pCMS}\left(10^{-7} \mathrm{M}\right)$ before the addition of fraction II $(5 \mathrm{mg} / \mathrm{ml})$ and endotoxin $(0.005-0.01 \mu \mathrm{g} / \mathrm{ml})$ completely inhibited the subsequent reaction. Polyvinylsulfate and all other inhibitors tested had no effect on fraction I (Table I). Preincubation of fraction II $(5 \mathrm{mg} / \mathrm{ml})$ with DIFP, $\mathrm{pCMB}$, or $\mathrm{pCMS}$ $\left(10^{-4}-10^{-5} \mathrm{M}\right)$ did not inhibit the reaction after the addition of the remaining two components. DIFP was the only one of these three reagents that inhibited the reaction when preincubated with endotoxin.

To determine whether gelation of fraction II by endotoxin, in the absence of added fraction I, was due to contamination of fraction II with fraction I, fraction II was preincubated with DIFP, $\mathrm{pCMB}$, or pCMS before the addition of endotoxin. Gelation of fraction II by endotoxin was completely inhibited when inhibitors of fraction I were present.

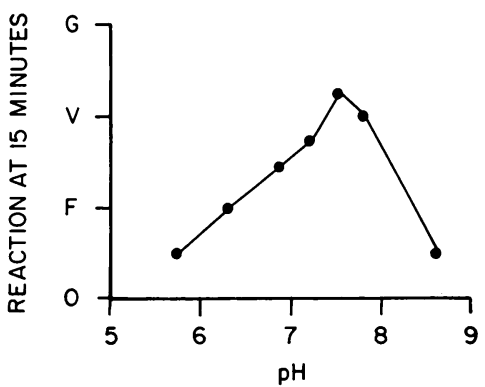

FIgURE 10 The effect of $\mathrm{pH}$ on the rate of the reaction between fractions I and II with endotoxin. Each reaction mixture consisted of $0.005 \mathrm{ml}$ of fraction $\mathrm{I}(6 \mathrm{mg} / \mathrm{ml}), 0.05$ $\mathrm{ml}$ of fraction II $(5 \mathrm{mg} / \mathrm{ml}), 0.005 \mathrm{ml}$ of endotoxin (1 $\mu \mathrm{g} / \mathrm{ml}$ ), and $0.045 \mathrm{ml}$ of buffer, and was incubated at $37^{\circ} \mathrm{C}$. Phosphate buffers, $\mathrm{pH}$ 5.7-7.9, or veronal buffers, $\mathrm{pH}$ 7.2-8.6, were used. F, flocculation; V, increased viscosity; G, gel. The rate of the reaction was dependent upon the $\mathrm{pH}$, with an optimum at $\mathrm{pH} 7.5$.
TABLE I

Effects of Enzyme Inhibitors on the Reaction of Whole Amebocyte Lysate or Fraction I with Endotoxin*

Inhibitors of whole amebocyte lysate

diisopropyl fluorophosphate $\left(10^{-6} \mathrm{M}\right) \ddagger$

para-chloromercuribenzoate $\left(10^{-6} \mathrm{M}\right)$

para-chloromercuriphenyl sulfonate $\left(10^{-6} \mathrm{M}\right)$

polyvinylsulfate $\left(10^{-3} \mathrm{M}\right)$

Inhibitors of fraction I

diisopropyl fluorophosphate $\left(10^{-4} \mathrm{M}\right) \ddagger$

para-chloromercuribenzoate $\left(10^{-4} \mathrm{M}\right)$

para-chloromercuriphenyl sulfonate $\left(10^{-7} \mathrm{M}\right)$

Agents which did not inhibit lysate or fraction I $\left(10^{-3} \mathrm{M}\right)$

alpha, alpha'-dipyridyl

disodium ethylenediamine-tetraacetate

iodoacetate

N-ethyl maleimide

potassium cyanide

* Inhibitors of enzymatic reactions were incubated with whole amebocyte lysate or fraction $\mathrm{I}$ for $10 \mathrm{~min}$ at $37^{\circ} \mathrm{C}$ and $\mathrm{pH} \mathrm{7.5.}$ $\ddagger$ Minimum concentrations required to produce a decreased reaction (inhibition of gelation) with endotoxin are shown in parentheses.

\section{DISCUSSION}

Lysates prepared from amebocytes of Limulus contain the entire coagulation system of this animal and are gelled by endotoxin (2). Low concentrations of endotoxin are capable of reacting with amebocyte lysate, and the rate of gelation is dependent upon the concentration of endotoxin $(2,3)$. It was suggested previously that endotoxin activated an enzyme which then produced gelation of the clottable protein $(2,3)$. However, direct evidence for an enzymatic process was lacking, and the components of amebocyte lysate were unknown. Previous studies indicated that the clottable protein of Limulus differed from mammalian fibrinogen and had a low molecular weight $(2,11)$.

In the present studies, three major fractions (designated I, II, and III) were demonstrated in amebocyte lysate using Sephadex column chromatography. No immunological cross-reactivity was seen on Ouchterlony analysis. Fraction II constituted approximately $50 \%$ of the protein in whole lysate and contained the clottable protein. The clottable protein was heat stable and had a molecular weight of approximately 27,000 . Fraction II was not present in the supernatant obtained after gelation of lysate by endotoxin, suggesting complete utilization of fraction II during gelation. Addition of endotoxin to fractions I or III did not result in gelation. 
Endotoxin was capable of producing gelation of fraction II, but the rate of the reaction was significantly increased by the addition of small concentrations of fraction I. The gelation of fraction II by endotoxin, in the absence of added fraction I, probably was secondary to contamination of fraction II with fraction I, since inhibitors of fraction I blocked this reaction. The accelerative effect of fraction $I$ on the reaction between fraction II and endotoxin was proportional to the concentration of fraction I. Activity of fraction I was destroyed by heating. The reaction of fractions I and II with endotoxin was temperature dependent and had a $\mathrm{pH}$ optimum of 7.5 . Preincubation of fraction $\mathrm{I}$ and endotoxin at $37^{\circ} \mathrm{C}$ accelerated the rate of the reaction and the degree of acceleration was proportional to the time of preincubation. Preincubation at $4^{\circ} \mathrm{C}$ did not produce this effect. These results suggested the formation of an activated factor $\left(I_{\mathbf{a}}\right)$. The "active factor" ( $\left.\mathrm{I}_{\mathbf{a}}\right)$ that resulted from incubation of fraction I with endotoxin was heat labile, suggesting it was an activated form of material contained in fraction I rather than endotoxin, which it heat stable.

Some enzymatic inhibitors blocked the reaction between fraction I, fraction II, and endotoxin. The results indicated that DIFP, $\mathrm{pCMB}$, and $\mathrm{pCMS}$ exerted their inhibitory effect upon fraction I. Incubation of similar concentrations of these inhibitors with fraction II had no effect upon the subsequent reaction of fraction II with fraction $I$ and endotoxin. These results suggest that fraction I contains an enzyme(s) in which sulfhydryl or hydroxyl groups may be functionally important, since DIFP is relatively specific for serine hydroxyl groups (12), and pCMS and $\mathrm{pCMB}$ are active against sulfhydryl groups $(13,14)$. Other inhibitors of enzymatic reactions, including metal binders, did not affect the reaction. EDTA was reported previously to inhibit the reaction (2). In the present studies, EDTA was not inhibitory at $\mathrm{pH} 7.5$, suggesting that previous observations were related to low $\mathrm{pH}$. Fraction I not only accelerated gelation but increased the degree of gelation, suggesting the possibility that it contributes to the structure of the gel. Sulfhydryl groups in fraction I could be enzymatically active and/ or contribute to the bonds necessary for physical formation of the gel. Insolubility of the gel in urea or 2mercaptoethanol indicates that gel formation is not solely the result of hydrogen or hydrophobic bond or disulfide bridge formation.

These data strongly suggest that the reaction between endotoxin and amebocyte lysate is enzymatic. The results indicate that endotoxin does not react directly with the clottable protein (in fraction II), but apparently activates an enzyme contained in fraction I which then gels the clottable protein. Activation of fraction I by endotoxin may be analogous to the activation of prothrombin to form thrombin $(15,16)$. The resultant enzyme(s) then reacts with the clottable protein to produce a gel, as thrombin reacts with mammalian fibrinogen to form fibrin $(15,17,18)$. Endotoxin has been reported to exert effects on mammalian blood coagulation $(19,20)$, complement $(21,22)$, and kallekrein $(23,24)$. Activation of these systems results in enzymatic alteration of their respective substrates.

Endotoxins are lipopolysaccharides which contain carbohydrates, carboxylic acids, amino acids, amines, and phosphorus, and consist of three major structural regions rich in polysaccharides, lipids, or amino acids (25). The polysaccharide region plays a major role in determination of antigenic specificity, amino acids may serve as connecting links between the lipopolysaccharide and the bacterial cell wall, and the lipid moiety apparently is responsible for many of the toxic effects of endotoxin (25). The lipid portion of the endotoxin molecule also is necessary for its reaction with both complement and amebocyte lysate $(3,26)$. The appropriate phospholipid must be present in tissue factor in order to result in acceleration of blood coagulation (27).

The coagulation system of Limulus represents a phylogenetically primitive host defense mechanism, which may have evolved and become extracellular and diversified to serve many functions in higher animals. Complement-like material has been detected in the blood of Limulus (28), and apparently can be activated by endotoxin (29). The activation of complement and blood coagulation in mammals by endotoxin may be based in part on this more primitive mechanism. Coagulation of amebocyte lysate may be similar to the gelation of a low molecular weight clottable protein of the seminal vesicle by the enzyme vesiculase to form the "copulation plug" of some mammals (30).

Amebocyte lysate has been shown recently to provide the basis for a useful, reliable method for the measurement of endotoxin in the plasma and other body fluids of patients suspected of having gram-negative sepsis $(5,31)$. Further isolation of the enzyme system in amebocyte lysate which is activated by endotoxin, but perhaps capable of a variety of proteolytic reactions, may lead to other rapid assays for endotoxin. Structural analysis of this enzyme and greater insight into its reaction with endotoxin may lead to better understanding of the biological effects of endotoxin.

\section{ACKNOWLEDGMENTS}

These investigations were supported in part by grants from the National Heart Institute (HE 01601) and the National Institute of Allergy and Infectious Diseases (AI 06927), National Institutes of Health, U. S. Public Health Service. 


\section{REFERENCES}

1. Young, N. S., J. Levin, and R. A. Prendergast. 1971. Endotoxin-clottable protein from the amebocytes of Limulus polyphemus. Fed. Proc. 30: 340. (Abstr.)

2. Levin, J., and F. B. Bang. 1968. Clottable protein in Limulus: its localization and kinetics of its coagulation by endotoxin. Thromb. Diath. Haemorrh. 19: 186.

3. Levin, J., P. A. Tomasulo, and R. S. Oser. 1970. Detection of endotoxin in human blood and demonstration of an inhibitor. J. Lab. Clin. Med. 75: 903.

4. Braude, A. I. 1964. Absorption, distribution, and elimination of endotoxins and their derivatives. In Bacterial Endotoxins. M. Landy and W. Braun, editors. Rutgers University Press, New Brunswick, N. J. 98.

5. Levin, J., T. E. Poore, N. P. Zauber, and R. S. Oser. 1970. Detection of endotoxin in the blood of patients with sepsis due to gram-negative bacteria. N. Engl. J. Med. 283: 1313.

6. Levin, J., and F. B. Bang. 1964. The role of endotoxin in the extracellular coagulation of Limulus blood. Bull. Johns Hopkins Hosp. 115: 265.

7. Ouchterlony, O. 1953. Antigen-antibody reactions in gel. IV. Types of reactions in coordinated systems of diffusion. Acta Pathol. Microbiol. Scand. 32: 231.

8. Scheidegger, J. J. 1955. Une micro-méthode d'immunoelectrophorèse. Int. Arch. Allergy Appl. Immunol. 7: 103.

9. Lowry, O. H., N. J. Rosebrough, A. L. Farr, and R. J. Randall. 1951. Protein measurement with the Folin phenol reagent. J. Biol. Chem. 193: 265.

10. Dawson, R. M. C., D. C. Elliott, W. H. Elliott, and K. M. Jones. 1959. Data for Biochemical Research. Oxford University Press, London, England.

11. Solum, N. O. 1970. Some characteristics of the clottable protein of Limulus polyphemus blood cells. Thrombos. Diath. Haemorrh. 23: 170.

12. Cohen, J. A., R. A. Oosterbaan, and F. Berends. 1967. Organophosphorus compounds. Methods Enzymol. 11: 686.

13. Cecil, R. 1963. Intramolecular bonds in proteins. I. The role of sulfur in proteins. In The Proteins. Composition, structure, and function. Vol. I. H. Neurath, editor. Academic Press, Inc., New York. 379.

14. Webb, J. L. 1966. Comparison of SH reagents. In Enzyme and Metabolic Inhibitors. Vol. III. Academic Press, Inc. New York. 795.

15. Lein, J. 1947. A photometric analysis of the reactions of blood coagulation. J. Cell. Comp. Physiol. 30: 43.

16. Grannis, G. F., L. A. Kazal, and L. M. Tocantins. 1965. The kinetics of thrombin activity in recalcified blood plasma. Thromb. Diath. Haemorrh. 13: 361

17. Ferry, J. D., and P. R. Morrison. 1947. Preparation and properties of serum and plasma proteins. VIII. The conversion of human fibrinogen to fibrin under various conditions. J. Amer. Chem. Soc. 69: 388.

18. Laki, K. 1965. Enzymatic effects of thrombin. Fed. Proc. $24: 794$.

19. Hjort, P. F., and S. I. Rapaport. 1965. The Shwartzman reaction: pathogenetic mechanisms and clinical manifestations. Ann. Rev. Med. 16: 135.

20. Beller, F. K. 1969. The role of endotoxin in disseminated intravascular coagulation. Thromb. Diath. Haemorrh. Suppl. 36: 125.

21. Gewurz, H., H. S. Shin, and S. E. Mergenhagen. 1968. Interactions of the complement system with endotoxic lipopolysaccharide: consumption of each of the six terminal complement components. J. Exp. Med. 128: 1049.

22. Hook, W. A., R. Snyderman, and S. E. Mergenhagen. 1970. Consumption of hamster complement by bacterial endotoxin. J. Immunol. $105: 268$.

23. Nies, A. S., M. J. Cline, and K. L. Melmon. 1968. Mechanism of activation of human plasma kallikrein by endotoxin. Clin. Res. 16: 157. (Abstr.)

24. Mason, J. W., U. Kleeberg, P. Dolan, and R. W. Colman. 1970. Plasma kallikrein and Hageman factor in gram-negative bacteremia. Ann. Intern. Med. 73: 545.

25. Nowotny, A. 1971. Relationship of structure and biological activity of bacterial endotoxins. Naturwissenschaften. 58: 397.

26. Mergenhagen, S. E., R. Snyderman, H. Gewurz, and H. S. Shin. 1969. Significance of complement to the mechanism of action of endotoxin. Curr. Top. Microbiol. Immunol. 50 : 37.

27. Nemerson, Y. 1968. The phospholipid requirement of tissue factor in blood coagulation. J. Clin. Invest. 47: 72.

28. Day, N. K. B., H. Gewurz, R. Johannson, J. Finstad, and R. A. Good. 1970. Complement and complementlike activity in lower vertebrates and invertebrates. $J$. Exp. Med. 132 : 941.

29. Gewurz, H., V. Birdsey, D. Johnson, J. Lindorfer, K. Townsend, and A. Gewurz. 1970. An inducible lysin in Limulus polyphemus with similarities to the complement system of vertebrates: detection, characteristics and dissection from phospholipase A. Biol. Bull. 139: 411. (Abstr.)

30. Notides, A. C., and H. G. Williams-Ashman. 1967. The basic protein responsible for the clotting of guinea pig semen. Proc. Nat. Acad. Sci. 58: 1991.

31. Levin, J., T. E. Poore, N. S. Young, S. Margolis, N. P. Zauber, A. S. Townes, and W. R. Bell. 1972. Gramnegative sepsis: detection of endotoxemia with the Limulus test with studies of associated changes in blood coagulation, serum lipids, and complement. Ann. Int. Med. 76: 1 